\title{
MAKING WAVES: EXAMINING THE INTERFACE BETWEEN CRUISE TOURISM AND DESTINATION COMMUNITY
} IN AKAROA, NEW ZEALAND

\author{
JUDE WILSON, MICHAEL C. SHONE, DAVID G. SIMMONS, AND EMMA STEWART \\ Lincoln University, Christchurch, New Zealand
}

\begin{abstract}
This article reports on a study of community attitudes to cruise tourism in Akaroa, New Zealand. An important dimension of this study is the significant rate of growth in cruise arrivals over a short period of time as the result of the 2010/11 Canterbury earthquakes. Data were collected via a postal survey of the Akaroa community, and yielded a response rate of $56.6 \%(n=316)$. The results indicate that despite the recent growth in arrivals, the Akaroa community holds a largely favorable opinion of cruise tourism. Importantly, the impacts identified by respondents were more closely aligned to threats to their identity as a destination, rather than problems with tourism, per se.
\end{abstract}

Key words: Akaroa; Cruise tourism; Destination community; Impacts

\section{Introduction}

Cruise tourism is increasingly recognized as a successful and dynamic subsector of the global tourism industry (Weeden, Lester, \& Thyne, 2011). Although the sector is now considered to be approaching "maturity" in Australasia, its ongoing expansion nonetheless represents a potentially lucrative form of tourism for destination communities across a range of locations. While destinations seek to embrace the industry's expansion, they also have to manage the often diverse needs of communities at the same time as protecting the local environment and minimizing any costs associated with being a sustainable cruise destination (Lester \& Weeden, 2004).

This article reports on a study of community attitudes to cruise tourism in the small harbor town of Akaroa, New Zealand. It does so in the context of a period of unprecedented change and disruption to the region's tourism sector as a consequence of the 2010/2011 Canterbury earthquakes. An important dimension of cruise tourism in Akaroa has been the arrival of large numbers of cruise visitors over a relatively short period of time; this growth trajectory contrasts markedly with the more incremental tourism growth patterns of land-based visitors experienced in Akaroa to date. Historically a busy 
tourism destination with well-documented visitor impacts, cruise tourism presented the Akaroa community with a new set of perceived visitor impacts.

\section{Community Perspectives of Cruise Tourism}

While research on community attitudes toward tourism is a long-standing research theme, research on community perspectives of cruise tourism in particular is a relatively new addition in the academic literature. Within this emergent literature, attitudes to cruise tourism appear to be heterogeneous. Studies have found that not all communities are welcoming of cruise passengers (Brida, Riaño, \& Zapata, 2011; Hritz \& Cecil, 2008) and, even in those destination communities where cruise tourism is welcomed and supported, residents have articulated a variety of both positive and negative views in the context of a rapid increase in cruise ship arrivals (Stewart, Dawson, \& Draper, 2011). Although few studies have specifically addressed the impact of cruise ships on small communities, there is a large body of literature regarding the relationship between residents and visitors, and how tourism impacts upon local communities. The development of this scholarship can, arguably, be traced back to the work undertaken initially by Doxey (1975) and followed by many others. According to Pearce, Moscardo, and Ross (1996), one striking conclusion that can be drawn from this pool of research is that there are few consistent relationships or patterns. This inconsistency is reinforced in other reviews of this material (Ap, 1990; Harril, 2004; King, Pizam, \& Milman, 1993).

Gibson and Bentley (2006) note that the "social effects" of tourism are broad ranging; they refer to the ways in which tourism contributes to changes in value systems, family relationships, individual behavior, safety levels, moral conduct, collective lifestyles, creative expressions, traditional ceremonies, and community organizations. Other social impact issues such as crowding in destination areas and the disruption created by routing and activities associated with cruise tourism (e.g., embarking and disembarking passengers) have been identified as a problem in cruise tourism destinations (Brida \& Zapata, 2010; Klein, 2002). In their study on residents' quality of life, Kim, Uysal, and Sirgy (2013) found that perceptions of tourism impacts (i.e., economic, social, cultural, and environmental) influence resident well-being in corresponding life domains (e.g., material life, community life, emotional life, and health and safety).

More recently, authors such as Deery, Jago, and Fredline (2012) have attempted to provide an alternative conceptual framework for understanding social impacts of tourisms on host communities. They note the existence of a number of external variables influencing residents' perceptions of tourism impacts (e.g., economic dependence on tourism, level of contact with tourists, tourist/resident ratio), value-based variables (e.g., community attachment, and social, political, and environmental values), and specific social impacts (e.g., economic benefits, opportunity cost, delinquent behavior). They also propose that social impact research aims to provide a deeper understanding of why some impacts are more important to residents than others. This follows Ap's (1992) earlier work using a social exchange process model as a theoretical framework to better understand how tourism impacts are perceived. As Ap (1992) noted, this model can "accommodate explanation of both positive and negative perceptions, and can examine relationships at the individual or collective level" (p. 667). The goal is to achieve outcomes that obtain the best balance of benefits and costs for both residents and tourism actors. Thus, if benefits of tourism activity outweigh costs, perceptions may change to a more positive disposition, despite initial opposition. Importantly, Ap (1992) proposed that community "type" affects which social impact variables are significant in respect of destination management.

As early as 1975, however, Doxey (1975) signaled future research scenarios in which possible irritants arising from tourism could be clustered and weighted relative to the attributes of the "ideal tourist" and "ideal type of industry" for any given destination. Doxey (1975) postulated that at any given destination, there exists reciprocating impacts between visitors and residents, and that the extent to which these are regarded as irritations will be determined primarily by the mutual compatibility of each. According to Doxey (1975), the problem for destination planners and managers lies with the distinction between structural changes (i.e., widespread changes which change the nature of the existing industry) and dimensional changes 
(i.e., associated with expansion without a basic change in the nature of the industry). In both situations of change, the fundamental concern relates to the impact of visitors on the value system and lifestyle of the destination.

This paradigm was also noted in early work by Butler (1974), theorizing that the social impact of tourism upon a destination area is closely related to the extent to which it impacts on the resources used by local residents, their economic well-being, and their lifestyles. Butler (1974) identified five social impact factors related to the tourists (i.e., the number of visitors; length of stay; ethnic characteristics; economic characteristics; and their activities), and five social impact factors related to the characteristics of the destination area (i.e., economic state of the area; degree of local involvement in tourism; spatial characteristics of tourism development; viability of the local culture; and other characteristics, such as political attitudes). Butler (1974) noted, however, that it was extremely difficult to explain how these factors will combine in any one destination. Butler (1980) then moved on to develop his seminal Tourist Area Life Cycle (TALC) model (also known as the Resort Cycle), whereby destination areas are theorized as experiencing relatively universal development trajectories (i.e., growth, decline, and/ or stagnation). A range of complementary models (e.g., Cohen, 1972; Doxey, 1975; Keller, 1987) is often posited alongside Butler's model, in order to provide a conceptual link between destination development and the evolution of tourist typologies, hierarchies of control and capital input, and community perceptions of tourism.

After more than 30 years of exposure, however, there appears to be a consensus that the "Butler sequence" represents but one evolutionary scenario among a range of destination possibilities (e.g., Weaver, 2000). Significantly, Butler (1980) himself alluded to situations where the TALC development model could be accelerated or even circumvented altogether by the occurrence of "atypical" destination development trajectories (Butler, 2006). A result of this critique is the creation of alternative models of destination development within the academic literature. These include, for example, Weaver's (2000) Broad Context Model, in which various bilateral scenarios of destination development can be situated and assessed in terms of their prevalence and likelihood. Another model is offered by Prideaux (2000), whose Resort Development Spectrum notes progressive phases of development facilitated by the expansion of infrastructure and parallel development of new market sectors.

\section{The Study Setting}

The small coastal township of Akaroa is located in Akaroa Harbour, one of two volcanic craters that form Banks Peninsula, on the east coast of New Zealand's South Island; Christchurch's Port of Lyttelton is located in the other crater (Fig. 1). At the March 2013 census, Akaroa had a "usually resident population” of 624 people occupying 342 dwellings (Statistics New Zealand, 2014). An additional 567 dwellings were unoccupied at the time of the census; the majority of these are nonresident-owned holiday homes and are occupied primarily on weekends and during holiday periods. The town also acts as a service center for the scattered population of the outer bays area of Akaroa Harbor. Many of these “outer bays" residents are employed in Akaroa.

Akaroa's location, 75 km from Christchurch, makes it an easily accessible destination for day and overnight visits. The town has a long history of tourism development and visitation, and is actively promoted as one of the apex visitor destinations in the Canterbury region for both international and domestic travelers. Visitors are attracted by Akaroa's village charm and French heritage, the surrounding rural landscapes and coastal scenery, and easily accessible marine wildlife. Akaroa Harbor is popular with recreational boat users and provides safe anchorage-although berthing is not possible-to visiting cruise ships.

The range of different types of overnight visitors (e.g., holiday homeowners, international and domestic tourists), and the influx of day visitors at busy times makes it difficult to measure accurately the level of tourism visitation and activity in Akaroa. Sleeman (2008) reported an estimated 3,300 day and overnight visitors per day in midJanuary 2003; recent media reports suggest a daily influx during the busy summer period of over 5,000 visitors (both overnight and day visitors) (Hampton, 2013). For a settlement of its size, Akaroa is "oversupplied" with tourism-related public amenities and services, (e.g., shopping facilities, cafés, and 


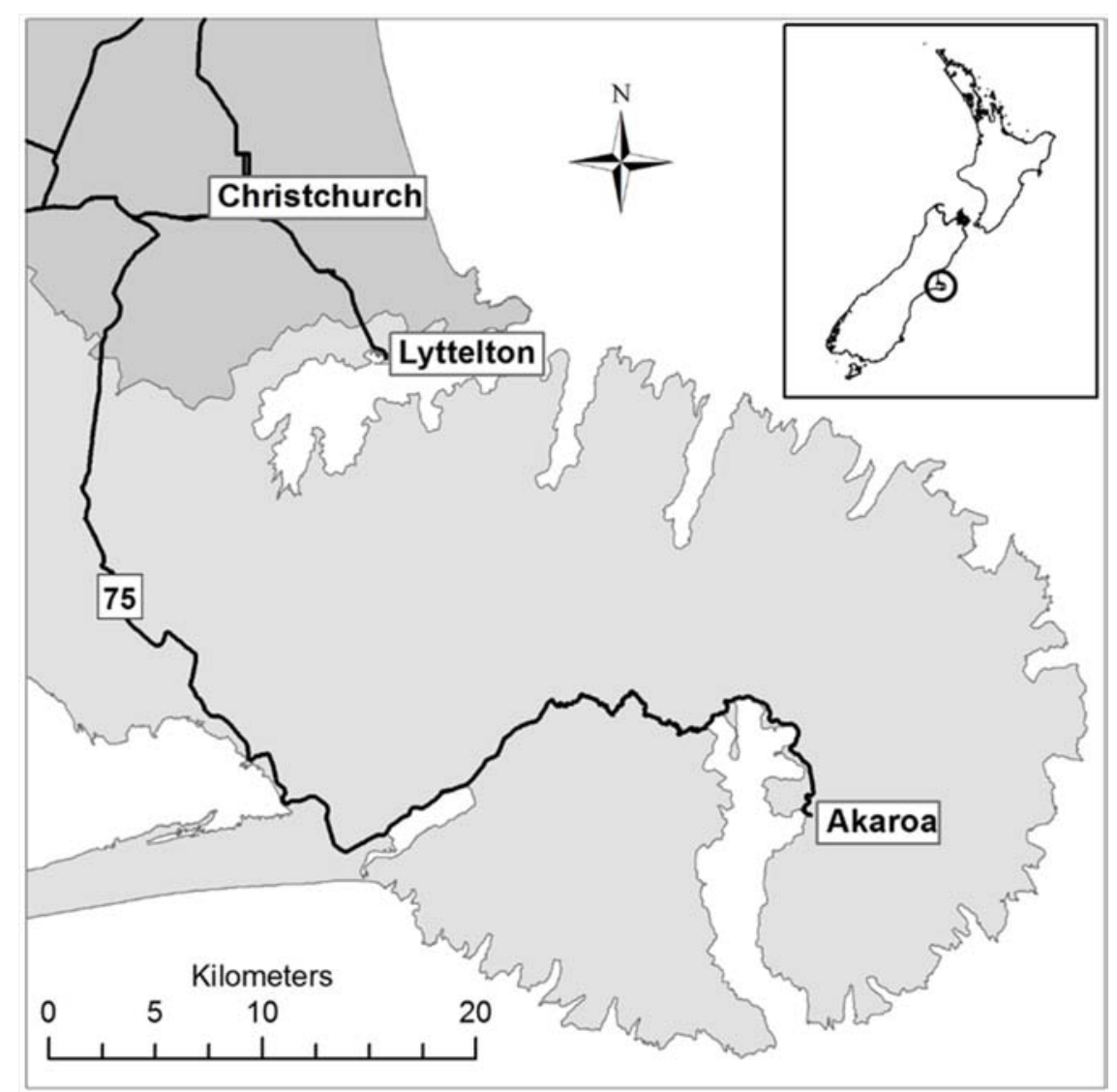

Figure 1. Map showing Akaroa location.

restaurants), but is less well-catered for in respect of resident services (e.g., health care, banking services, and so on).

Shone, Simmons, and Fairweather (2003) examined host community perceptions, expectations, and adaptations to tourism in Akaroa in 2003, reporting that despite high levels of tourism visitation during peak times, residents were supportive of ongoing growth of tourism in Akaroa and, in particular, referenced the economic benefits associated with employment in the sector. Akaroa residents valued the town's natural setting, peacefulness, and village atmosphere and identified a number of specific tourism-related problems - such as strain on infrastructure and congestion-that threatened this. A high likelihood to alter shopping behavior and leisure activities during times of peak visitation, and to holiday away from the town during these peak times in order to "escape" the incoming visitors, were also reported (Shone et al., 2003).

More recent tourism carrying capacity research in Akaroa also notes the importance of the tourism industry to the long-term sustainability of Akaroa; without a strong tourism industry the township would experience increased unemployment, reduced economic activity, and a potential loss of population through a migrating workforce (Sleeman, 2009). Once again, however, a number of tourism-related issues were also identified, including: traffic congestion, parking availability, the impact of cruise tourism and major events, crowding, and a range of infrastructure maintenance and capacity issues. Parking issues in Akaroa had been the subject of a series of annual monitoring surveys (see Thompson, 2006, 2007, 2008). With specific reference to cruise tourism, Sleeman (2009) notes 
the "negative impact of large cruise ships is less than first thought" (p. 14), although at that time the level of cruise tourism was significantly lower than at present (i.e., cruise ships presented in the harbor on only 15 days between November and March). The issue of crowding created by pedestrian traffic, and the contribution of cruise tourism to that crowding, was noted as being significant during peak times during the day, although this also provided increased business opportunities.

\section{Cruise Tourism in Akaroa}

As a result of damage to Lyttelton Port in Christchurch in the 2011 Canterbury earthquakes Akaroa experienced sudden and significant growth in cruise tourism (see Table 1). Prior to this Akaroa generally hosted smaller ships, but had experienced steady growth in both the number and size of ships visiting. At the time, cruise tourism was the fastest growing tourism sector in New Zealand, and was significant in the context of the overall downturn in international visitor growth as a result of the global economic recession of the mid- to late 2000s.

In each of the two postearthquake seasons, more than 80 cruise ships arrived in Akaroa Harbour. This amounted to approximately 70-74 visit days per cruise season (October-April), during which between 2,000 and 4,000 cruise visitors could disembark. However, anecdotal evidence suggested that around a third of these visitors stayed onboard ship, a third came ashore to spend time in Akaroa, and a final third came ashore, but departed Akaroa for more distant daytrip locations (e.g., Christchurch city and the wider Canterbury region).

Towards the end of the 2012/2013 cruise season the Akaroa Mail published a letter in which a local resident voiced concerns around cruise tourism in Akaroa and, in particular, the impact hosting so many ships was having on the local community. The resultant flurry of responses generated considerable public debate in Akaroa and gained some regional and nationwide media exposure (e.g., Radio New Zealand Newswire, 2013). While the media attention focused on the negative impacts of cruise tourism, in reality the majority of published items and local missives were strongly in favor of cruise tourism in Akaroa. The public outcry, however, was loud enough to initiate a research project to assess community perceptions of cruise tourism in Akaroa.

\section{Methods}

The survey, which sought to measure community attitudes to cruise tourism in Akaroa and to identify impacts (both positive and negative) of cruise tourism, included: questions developed from earlier Akaroa impact research (Shone et al., 2003); specific measures of the impact items identified in media reports and residents' letters; and incorporated attitude scales used in more generic social impact of tourism research (Haley, Snaith, \& Miller, 2005). Data were also collected on respondents' age, ethnicity, gender, employment status, their length of residence or association with Akaroa, employment in tourism-related jobs, and contact with cruise ship visitors. While initially conceptualized as a resident survey (i.e., including only permanent residents who lived within the town boundaries), the sampling parameter was extended to better encapsulate the Akaroa "community"- this included permanent residents, holiday home owners (many of whom are most often in residence during the cruise season), and a selection of residents from "outer bays"

Table 1

Cruise Tourism Activity in Akaroa: 2008-2013

\begin{tabular}{lcccc}
\hline $\begin{array}{l}\text { Cruise Season } \\
\text { (Year) }\end{array}$ & $\begin{array}{c}\text { No. of Ships } \\
\text { Visiting Akaroa }\end{array}$ & $\begin{array}{c}\text { Total Crew } \\
\text { Arrivals }\end{array}$ & $\begin{array}{c}\text { Total Passenger } \\
\text { Arrivals }\end{array}$ & $\begin{array}{c}\text { Change in } \\
\text { Passenger Arrivals }\end{array}$ \\
\hline $2008 / 2009$ & 9 & 1,793 & 4,882 & - \\
$2009 / 2010$ & 8 & 3,657 & 8,754 & $+79.3 \%$ \\
$2010 / 2011$ & 16 & 9,126 & 21,067 & $+140.7 \%$ \\
$2011 / 2012$ & 86 & 48,876 & 125,667 & $+496.5 \%$ \\
$2012 / 2013$ & 85 & - & 144,956 & $+15.3 \%$ \\
\hline
\end{tabular}

Source: Cruise New Zealand. 
and rural hinterland (most of whom either worked, or had strong social and community attachment to Akaroa).

While essentially a postal survey, survey packs (survey form, information sheet, and reply-paid envelope) were distributed door-to-door to Akaroa residents (one per household) and to Akaroa workplaces; they were also available for collection at the local council service center. Holiday home owners received survey packs by post. A letter alerting residents to the impending survey was published in the Akaroa Mail. Altogether, surveys were returned by 181 residents (286 distributed; 63.3\% response rate), 85 holiday homeowners (200 distributed; $42.5 \%$ ), and 50 district residents (72 distributed; $69.4 \%$ ). The overall response rate was $56.6 \%$. The research was undertaken in May 2013, after two "postearthquake" cruise seasons in Akaroa.

The survey data were entered into a Microsoft Excel spread sheet and all numerical data transported to SPSS 20 (Statistical Package for Social Sciences) for statistical analysis. Open-ended questions were coded to facilitate some basic statistical analysis and further analyzed and coded for key themes and types of responses. The data presented here relates to: scale item data (measuring general attitudes and specific issues); data collected via a closed-option question on the benefits from cruise tourism; and, data collected via open-ended questions addressing the benefits and problems/issues associated with cruise tourism. Together, these provide considerable insight into impacts of cruise tourism on the Akaroa community. We also present analysis of responses to the "any further comments" request that concluded the survey; more than half of all respondents $(n=169$, $53.5 \%)$ provided additional comments. These data were coded thematically and provided important contextual insight into the community attitudes. Data are reported for the total sample unless otherwise indicated; the full survey report includes detailed data analysis by sample group (Wilson \& Shone, 2013).

\section{Results}

Altogether, $75.6 \%(n=194)$ of the total sample were aged 55 years or over, reflecting the high number of retired people in Akaroa and the older ages at which people have the required capital to own a holiday home. Over a third of the sample were not in the workforce. Slightly over $60 \%$ of the sample were female and 98\% were of New Zealand European ethnicity. All three sample groups reported a long association with Akaroa: $62.4 \%$ of the residents had lived there 10 years or longer; $76.2 \%$ of the holiday homeowners had owned their Akaroa properties for 10 years or longer; and $73.9 \%$ of the district sample had lived in the area for 10 years or longer. Altogether, $39.2 \%$ of the sample had worked in at least one tourism-related job in the previous year. More than three quarters of the sample reported some contact (42\% sometimes, 39\% frequent) with cruise ship visitors; a further $11 \%$ reported that they rarely had contact and $8 \%$ had no contact.

\section{General Attitudes Towards Cruise Tourism}

Twenty-four statements (13 positive and 11 negative) were used to measure the general attitude of respondents to cruise tourism in Akaroa. Respondents were asked to rate their agreement with each item on a 5-point Likert-type scale (1 = strongly disagree; 5 = strongly agree). Overall, the positive statements attracted higher levels of agreement than did the negative ones. Mean scores higher than 3 were recorded for only two of the negative statements, compared to eight of the positive statements. The positive item attracting the highest level of agreement was that "cruise ship tourism improves the Akaroa economy" (mean $=4.38$, SD = 0.894; $58.5 \%$ strongly agreed); the negative item attracting the highest level of agreement was "cruise ship tourism increases traffic congestion in Akaroa" (mean = 3.65 , SD = 1.177; $26.9 \%$ strongly agreed).

Responses were also collated to derive a mean overall attitude "score" for each respondent, with the negative items "flipped" to standardize ranking scores. Slightly over half of the sample ( $n=161$, $52 \%$ ) were neutral (i.e., mean $=3)$; $25 \%(n=79)$ were negative (mean $<3)$; and $23 \%(n=73)$ were positive (mean $\geq 4$ ).

\section{Akaroa-Specific Issues}

A 5-point scale (1 = no problem; 2 = slight problem; 3 = moderate problem; 4 = significant problem; 5 = very significant problem) was used to measure the degree of impact of 12 cruise tourism-related issues in Akaroa. These issues were identified 
from the media reports that triggered this research. Around a third of respondents identified four issues as being either significant or very significant: strain on facilities and infrastructure (36.8\%); crowding in public buildings (36.1\%); crowding on footpaths (33.2\%); and traffic congestion (31\%). Crowding in cafés and restaurants and crowding in retail stores were perceived by more than half of all respondents (i.e., $64.2 \%$ and $60.6 \%$, respectively) to cause slight or moderate problems. The issues with the highest number of "no problem" responses were increased noise (52.4\%), increased litter (39.6\%), displacement of other visitors (33.2\%), and lack of parking for locals (30\%) (Fig. 2).

Respondents were also asked to identify cruise tourism-related problems and issues in an openended question. To avoid leading respondents on, this question appeared in the survey prior to the previous question about Akaroa-specific issues. Altogether, 209 respondents (66.1\% of the sample) identified 486 issues, many of which were reported multiple times. These issues were coded into five broad categories-facilities and amenities, overcrowding and congestion, bus/tour coach related, visitor management, and environmental issuesand then into subcategories (see Table 2). It was notable that many of the specific issues identified related to visitors and the visitor experience, rather than the local community. The greatest concerns with respect to visitors related to the provision and quality of facilities and amenities (particularly toilets), visitor safety, and the quality of visitor experience available to cruise ship visitors. By contrast, community issues related to those identified as having significant impacts on community life: congestion in public spaces and commercial premises; congestion on the roads, including on the main highway to Christchurch; and environmental concerns, relating to both the physical resources in the harbor and the social and cultural environments of the community itself.

\section{A Balanced View}

To ensure a balanced survey, the questionnaire also included several questions asking about benefits from cruise tourism. When asked if they thought Akaroa benefited from cruise tourism, 89\% of all respondents agreed, with $47 \%$ reporting that Akaroa benefited "greatly" (Fig. 3). A significant relationship $\left[\chi^{2}(8,300)=190.96, p<0.000\right]$ was found between perceptions of benefits to Akaroa from cruise tourism and overall attitude scores. As noted above, an attitude score of $\geq 4$ represents a positive attitude towards cruise tourism, a score of 3 represents a neutral attitude, and a score of $<3$

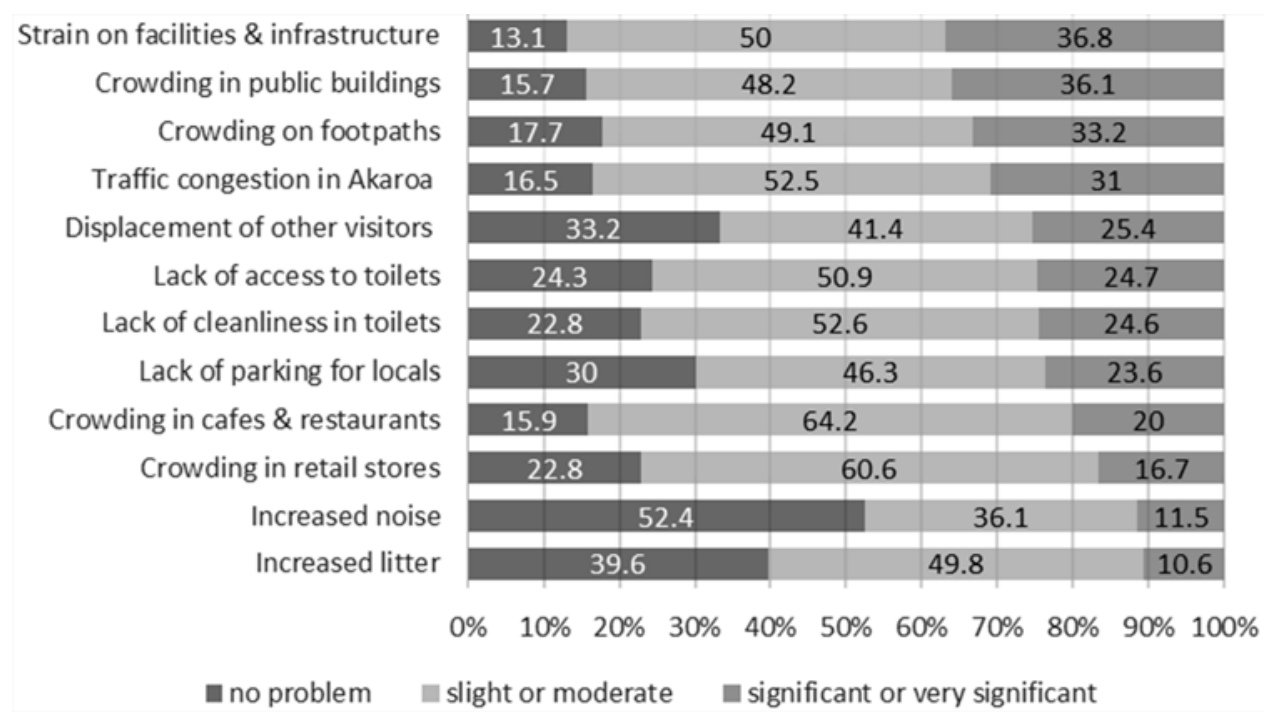

Figure 2. Akaroa-specific issues: perceptions of problems. 
Table 2

Cruise Tourism Issues, Broad and Subcategories, Impact Relationships ( $n=$ Number Reporting Issue)

\begin{tabular}{|c|c|c|}
\hline Cruise Tourism Issues & $\begin{array}{l}\text { Community } \\
\text { Impacts }\end{array}$ & $\begin{array}{l}\text { Visitor } \\
\text { Impacts }\end{array}$ \\
\hline \multicolumn{3}{|l|}{ Facilities and amenities $(n=137)$} \\
\hline Toilet specific (number/quality) & & $\mathrm{xxx}$ \\
\hline Other visitor facilities and amenities & & $\mathrm{xxx}$ \\
\hline Township issues (appearance/investment) & $\mathrm{xx}$ & $\mathrm{x}$ \\
\hline Wharf related (facility/boat impacts) & $\mathrm{x}$ & $\mathrm{xx}$ \\
\hline \multicolumn{3}{|l|}{ Overcrowding and congestion $(n=121)$} \\
\hline Akaroa overall (number of ships at one time) & $\mathrm{xxx}$ & \\
\hline Within Akaroa (specific town locations) & $\mathrm{xxx}$ & \\
\hline \multicolumn{3}{|l|}{ Bus/tour coach related $(n=119)$} \\
\hline Increased traffic & $\mathrm{xxx}$ & \\
\hline Impact on township (parking/fumes) & $\mathrm{xx}$ & $\mathrm{x}$ \\
\hline \multicolumn{3}{|l|}{ Visitor management $(n=66)$} \\
\hline Walking on road & $\mathrm{x}$ & $\mathrm{xx}$ \\
\hline Other visitor behaviors & $\mathrm{xx}$ & $\mathrm{X}$ \\
\hline Visitor safety and exposure & & $\mathrm{xxx}$ \\
\hline Quality and management of experience & $\mathrm{x}$ & $\mathrm{xx}$ \\
\hline \multicolumn{3}{|l|}{ Environmental problems $(n=43)$} \\
\hline Physical (underwater habitat/fuel pollution) & $\mathrm{xxx}$ & \\
\hline Social and cultural (community division/atmosphere) & $\mathrm{xxx}$ & \\
\hline
\end{tabular}

x, some impact; xx, moderate impact; $\mathrm{xxx}$, significant impact.

represents a negative attitude. Just over half (50.3\%) of those who thought Akaroa benefitted greatly had a positive attitude score (with another $48.8 \%$ neutral) and, conversely, just over half (51.2\%) of those who reported slight benefits were neutral, with the remainder (48.8\%) negative. All of the respondents who reported "no benefits" to Akaroa from cruise tourism had a negative attitude score.

Respondents were also asked to identify specific benefits from cruise tourism in Akaroa via an openended question. Altogether, 265 respondents (84.4\% of the total sample) identified 730 benefits, many

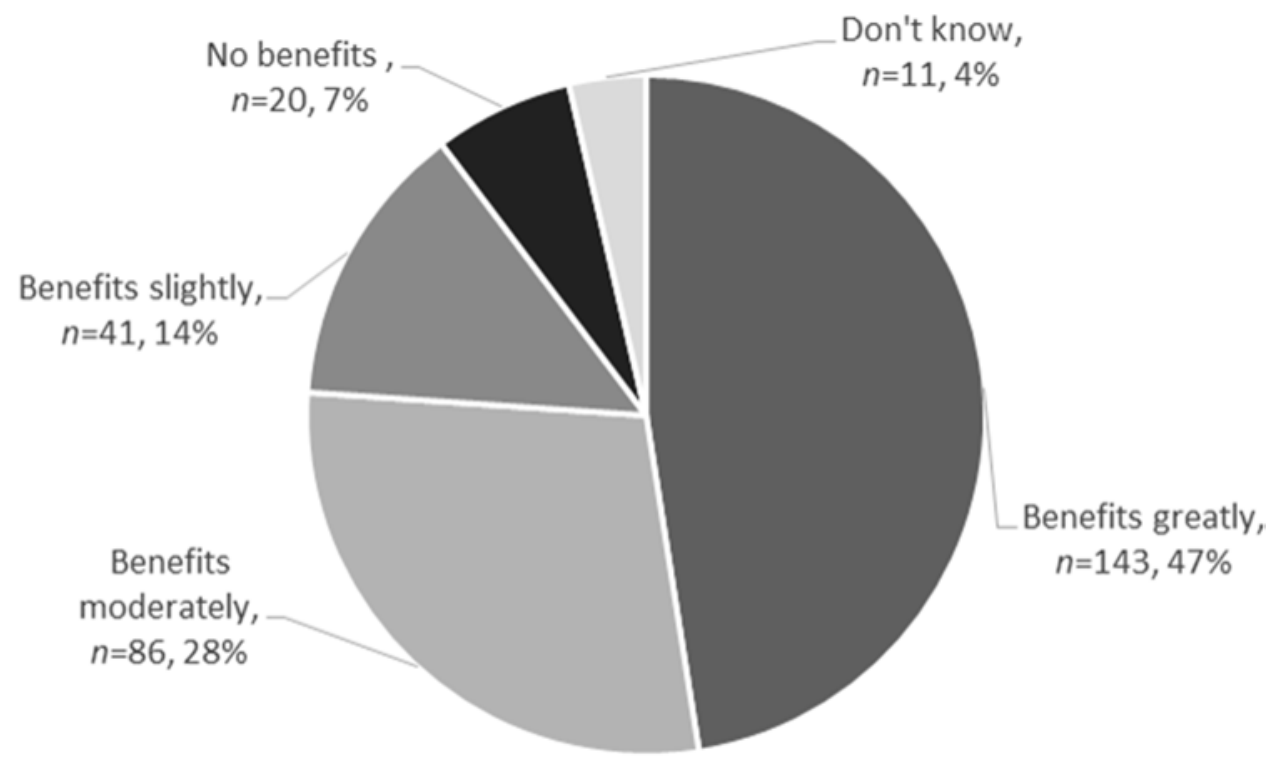

Figure 3. Perception of benefits from cruise tourism in Akaroa. 
of which were noted multiple times. These benefits were coded into four broad categories for ease of interpretation-economic, tourism related, community and social, and employment - and then into subcategories (see Table 3). In contrast to the problems identified in the corresponding issues question, the vast majority of the benefits identified related to the Akaroa community; the exception to this was some recognition that the economic benefits of Akaroa hosting cruise ships extended beyond the immediate community into the wider Canterbury region. While economic and employment benefits stood out strongly (together accounting for 51\% of the benefits reported), the other two categories suggested that the Akaroa community has a positive view of cruise tourism. A further $27.5 \%$ of the benefits were tourism related (and were primarily in favor of increased tourism), while the remaining $21.5 \%$ described enjoyment and appreciation of what tourism brought to the community.

\section{Cruise Tourism in Context}

On completion of the survey respondents were invited to make "any further comments" and, as

\section{Table 3}

Cruise Tourism Benefits, Broad and Subcategories ( $n=$ Number Reporting Benefit)

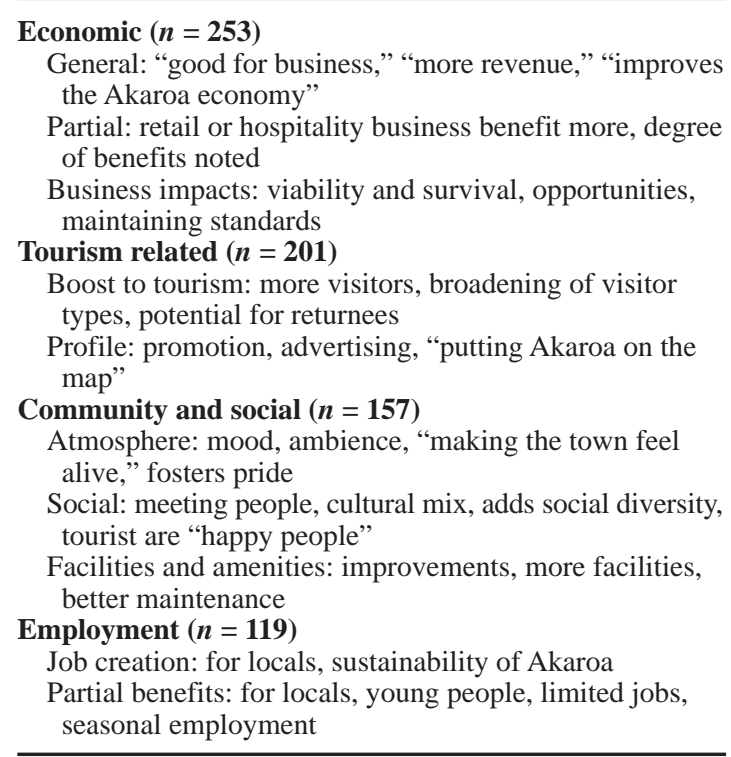

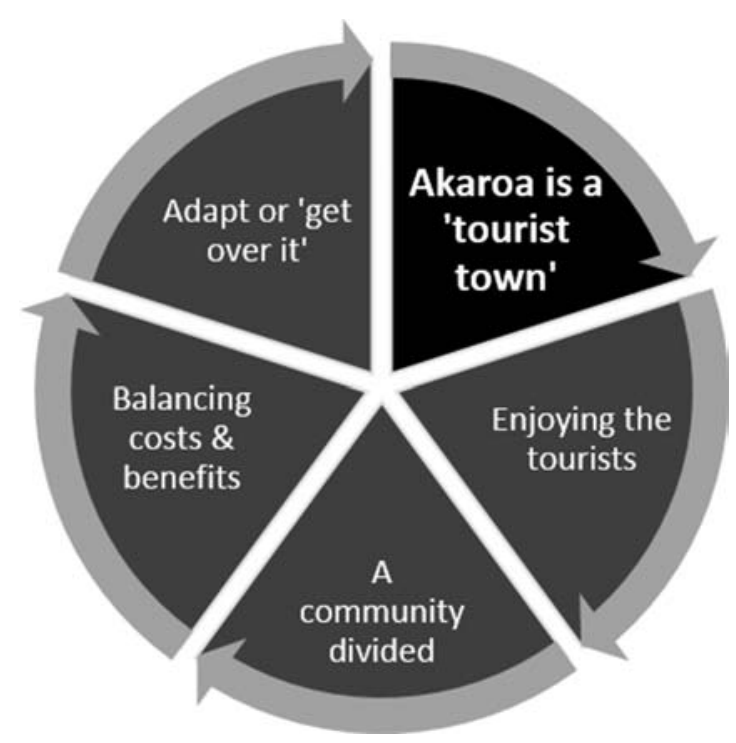

Figure 4. Themes identified in additional comments.

noted earlier, more than half of the sample $(n=169$, $53.5 \%$ ) responded. Many respondents wrote a full page of comments; some typed up extra pages and attached them to their survey form. While in some cases these comments simply reiterated or elucidated data already provided throughout the survey, in many instances respondents took the opportunity to provide a broader overview of their perceptions and opinions of cruise tourism and its impact on Akaroa. These comments were analyzed thematically, independent of the survey analysis, and were coded under five broad, and interrelated, headings and provide a structure for our discussion (Fig. 4). The central theme-and starting point — of the discussion is that Akaroa is a "tourist town."

\section{Discussion}

For the majority of respondents cruise tourism simply represents a new form of tourism in what is already an established destination (see, e.g., Prideaux, 2000). Some, however, questioned whether cruise tourism was the best type of tourism for Akaroa, particularly as the large influx of people on cruise ship days often coincided with traditional busy visitor periods; also cruise tourism did not benefit the established tourism sector equally (e.g., accommodation providers do not benefit). There was widespread 
recognition that cruise tourism raised Akaroa's profile as a tourism destination and that there was potential for these visitors to return (especially given many cruise ship passengers were Australian). As one respondent noted, small traffic inconveniences are "a natural and normal part of living in a tourist town." Others expressed a longer term view, noting that "tourism is Akaroa's future" and that "[Akaroa] needs to keep evolving to stay a viable tourism destination.” The quality of experience Akaroa is able to offer cruise tourists was a predominant theme; many of the individual issues identified in Table 2 point to this. However, some did express broader concerns around future tourism development that cruise tourism might stimulate, commenting that " $[\mathrm{I} \mathrm{am}]$ aware of the fine balance between Akaroa au natural and Akaroa overdeveloped."

The largely positive overall attitude to cruise tourism also supports a "tourist town" identity and function in a general sense, albeit articulated differently by the three community groups. This view of cruise tourism as an important component within the broader palette of tourism activity in Akaroa is reflected across a range of comments. The largely retired resident group, for example, recognizes the economic and employment benefits tourism affords the wider community and acknowledged tourism's contribution in respect of the range of community services they enjoy. The outer bays' respondents, while they did not live within the township boundaries, nevertheless made up a large proportion of the Akaroa community employed in tourismrelated jobs and relied on Akaroa as service center. This group was also the most directly affected by some of the issues identified as problematic (e.g., increased traffic). Enjoyment and appreciation of the tourism-related aspects of Akaroa was a strong theme in the nonresident holiday homeowners' responses; at the same time it was rarely explicitly acknowledged that they themselves were "visitors" to Akaroa. Their participation in this community survey also indicates a strong sense of community attachment. These findings suggest that Butler's (1974) social factors represent both greater importance, and more complexity, than do any of the tourist-related factors he identified.

The second theme-enjoying the tourists_-also underpins this tourist town identity. Many respondents reported that they enjoyed the tourists and that they added to the vibrancy and atmosphere in the village. Respondents also enjoyed seeing cruise ships in the harbor and liked meeting the variety of people they brought to Akaroa. For many, it was "nice to see the town busy." Some community members were involved voluntarily in a "meet and greet" role, and expressed pride in showing off their town to these visitors. Others simply commented that they "were lucky to be able to share our beautiful town" and that "I love my town and am happy to share it." These findings provide evidence for the contention that tourism impacts may influence well-being across a range of life domains (Kim et al., 2013).

Widespread concern that cruise tourism had engendered "a divided community" was the third theme to emerge. Although many of the tangible (and quantifiable) social impacts identified by Ap (1990) and Gibson and Bentley (2006) were reported in Akaroa, the most serious concerns within the community related to the impact of the cruise tourism "debate" on community cohesion. As one respondent noted "the issue has divided the community." There were suggestions that "some locals have become unwelcoming of visitors," that "the complainers are a slap in the face to all the volunteers," and even that "[this] survey had potential to further divide the community." Others wrote that "there is a lot of short-sighted opposition to cruise ships" and questioned "why should a vocal few feel they should have Akaroa to themselves?"

The fourth theme-balancing the costs and benefits of tourism - encapsulated the importance of looking at the positive and negative tourism impacts as an interrelated whole. This survey collected detailed data on problems (e.g., Table 2) and their perceived magnitude (e.g., Fig. 2), and identified individual benefits (e.g., Table 3) and the overall perception of benefit (e.g., Fig. 3). The final balance sheet appears in favor of cruise tourism. The equity of benefits was of concern, however, and was another issue that divided the community, reiterating the importance of community type (Butler, 1974), and of understanding impacts at the community level (Ap, 1992). In Akaroa, the outer bays sample benefited most directly (through their employment in tourism), but were also impacted significantly (via traffic problems); the lives of those in the resident sample were enhanced by tourism (both materially and socially), but they were impacted by crowding 
generated by the influx of new (and unfamiliar) visitors. For the holiday homeowner group, the benefits and costs paralleled those reported by the residents, albeit to weaker degree.

With respect to cruise tourism in Akaroa, the most significant of Butler's (1974) tourist-related impact factors is the number of visitors-especially the arrival of these visitors at times when Akaroa is already busy. Among the positives of cruise tourism were the fact that it was not year-round (providing some respite) and that it had a longer season (and therefore was more beneficial economically) than traditional visitors to Akaroa. Furthermore, cruise tourism does not appear to impact on Akaroa as much as traditional tourism. While crowding was one of the most significant problems identified, this occurred only for short intense bursts compared to other visitor types (Shone et al., 2003); many of the traffic issues reported related to the main highway to Christchurch-and was often coupled with resentment that Akaroa was losing economic benefits by tourists not staying there for the dayrather than associated with historical parking issues in the town (Thompson, 2008); also, cruise tourists do not stay overnight and use fewer resources, such as water (Sleeman, 2008).

Despite this lighter "footprint" there was a strong sense of community discomfort associated with these new cruise visitors. Although this was expressed as concern around the provision of a good visitor experience, it also highlighted the extent to which Akaroa's community identity is aligned with their historical persona as a particular type of destination. At present, cruise tourism and Akaroa are not "mutually compatible” (Doxey, 1975). This also points to the importance of value-based variables (Deery et al., 2012) in respect of understanding the social impacts of tourism. Cruise tourism came at a time when Akaroa was experiencing the effects of a tourism downturn. Growth in international visitors had slowed as a result of the global economic crisis, while both international and domestic visitation was severely impacted by the Canterbury earthquakes. There was a certain amount of altruistic desire to help through tourism facilitation on a broader scale that went beyond their own community needs (Weaver, 2000).

Although there was some sense that, given time, the Akaroa community might adjust to these changed circumstances, the cruise tourism "issue" was complicated by uncertainty associated with its future in Akaroa. It was expected that the cruise ships would return to the Port of Lyttelton once it was repaired, although quite when this might be was unknown. As a result, there was an understandable reluctance to commit resources and energy further developing Akaroa as a cruise tourism destination. In turn, this exacerbated the community embarrassment over Akaroa's destination quality. In the interim some significant concerns were also emerging with respect to the environmental impacts of cruise tourism, and the potential for these to increase over time.

The final category of comments-adapt or "get over it"-reflects the view of many respondents that the cruise tourism "issue" in Akaroa (i.e., rapid growth, current impacts, and an uncertain future) had been overstated by cruise tourism opponents. As one respondent wrote: "[cruise tourism brings] overall benefits and no lasting impacts-locals just need to adapt.” Shone et al.'s (2003) research reported considerable adaptation by residents in Akaroa in the past. This point was elaborated upon by a respondent who pointed out that these new tourists were not all that different to traditional ones: "Locals know they have to adapt during noncruise days as well-they have always had to and generally holiday makers are worse in some ways, holiday-home visitors are not the best financially either."

Finally, with respect to the survey itself, the unexpected high level of community engagement with the cruise ship tourism issue also reinforced the importance of tourism to the Akaroa community. This was manifested in a number of ways. First, there was an extremely high level of social awareness of the survey, with some residents commenting that they had been looking forward to receiving their survey packs. Second, the response rate was very high for a community survey of this nature. Third, the amount of effort taken over completion of the survey and, in particular, the volume of data provided via the open-ended responses and the additional comments was truly astounding. Fourth, and finally, we believe that our survey methodology (employing both openended and closed questions) and approach (including the three community groups rather than just residents) gave voice to a representative Akaroa community. We would caution that those undertaking social impact research take care not to assume that the vocal few represent the majority. Further, 
recognizing the root causes and extent of community discontent is perhaps as important as the identification of individual impacts.

\section{Conclusion}

The increase in cruise tourism, and the rate and scale at which this increase has occurred, has created a variety of impacts for the Akaroa community. It has also created an extraordinary condition of destination development, in which evolutionary development has been punctuated by a period of revolutionary development (i.e., sudden, dramatic, and wide-reaching growth). Although this perhaps represents the atypical growth trajectory suggested by Butler (1980), it also presents significant challenges in respect of the applicability of both destination development and social impact models measuring change (such as Butler's TALC and Doxey's Irridex) that are too prescriptive.

This research found an Akaroa community that is highly engaged with the cruise tourism "issue" and its impacts; perhaps in itself fostered and elevated in importance in a destination that identifies itself so closely as "a tourist town." This high level of engagement is likely to also have been reinforced, at least in part, by respondents' length of attachment to Akaroa. The majority of respondents reported at least a decade of association-expressed either as property ownership or residence. Although it is unreasonable to expect that Akaroa had remained static over time as a destination, change was commonly slower to manifest, and presented more incrementally, than what has occurred as a result of this sudden and significant increase in cruise tourism arrivals as a result of the Canterbury earthquakes.

Taken together, the results of this research indicate that despite the recent growth in arrivals, the Akaroa community holds a largely favorable opinion of cruise tourism. The identification of a wide array of benefits, in particular, suggests that the majority of respondents recognize the value of cruise tourism, and enjoy the diversity that this form of tourism brings to Akaroa. Although cruise tourism can exacerbate destination capacity issues during peak times of visitation, and despite the scale and pace of cruise tourism growth in Akaroa, the majority of respondents seem welcoming of this relatively new market segment. Although some tangible cruise tourism-related issues were identified, for many respondents, there was as much concern around the growing cruise tourism debate (and its public manifestation) on the community itself. Importantly, the impacts that emerged here were more about a challenge to their identity as a tourist town rather than problems with tourism per se. Tourism destination identity, and the underlying values held by the individual community member's in that destination, therefore warrants further investigation.

\section{Acknowledgments}

The authors thank Brad Case for the preparation of the map shown in Figure 1. This project was supported by Christchurch and Canterbury Tourism (CCT) and the Christchurch City Council (CCC).

\section{Biographical Notes}

Jude Wilson is a tourism researcher at Lincoln University, New Zealand. Her research interests include: tourist decision making, earthquake impacts on accommodation providers' hosting experiences, change in holiday home destinations, and the impact of climate change on tourism. For the past 3 years she has worked with the New Zealand Tourism Industry Association to produce an annual State of the Tourism Sector Report.

Michael Shone is a lecturer in Tourism and Recreation at Lincoln University. His research interests include: tourism policy and planning, destination management, regional tourism development, and community-based research approaches to tourism. He has also been involved in the development of a tourism planning toolkit for local government in New Zealand.

David Simmons is a Professor of Tourism and the Director of Research Strategy and Development at Lincoln University. His research interests include: destination evolution, tourism policy and planning, and the financial, economic, and sustainable yield from tourism. David has worked on tourism planning issues in Cambodia (WWF), Mauritius (UNDP), Niue, Vanuatu (WTO/UNDP), Nepal (MFAT and WWF), India (WWF), Sarawak (E. Malaysia), and DPR (North) Korea (UN/WTO).

Emma Stewart is a senior lecturer in Parks and Tourism at Lincoln University, New Zealand as well as a Research Associate at the Arctic Institute of North America at the University of Calgary, Canada. Her research interests include: human dimensions of climate change, polar tourism, cruise tourism, environmental interpretation, and community-based research approaches. 


\section{References}

Ap, J. (1990). Residents' perceptions research on the social impacts of tourism. Annals of Tourism Research, 17(4), 610-616.

Ap, J. (1992). Residents' perceptions research on tourism impacts. Annals of Tourism Research, 19(4), 665-690.

Brida, J. G., Riaño, E., \& Zapata-Aguirre, S. (2011). Resident's attitudes and perceptions towards cruise tourism development: A case study of Cartage de Indias (Colombia). Tourism and Hospitality Research, 11(3), 187-202.

Brida, J. G., \& Zapata-Aguirre, S. (2010). Cruise tourism: Economic, socio-cultural and environmental impacts. International Journal of Leisure and Tourism Marketing, 1(3), 205-226.

Butler, R. W. (1974). The social implications of tourist developments. Annals of Tourism Research, 2(2), 100-111.

Butler, R. W. (1980). The concept of a tourist area resort cycle of evolution: Implications for management of resources. Canadian Geographer, 14(1), 5-12.

Butler, R. W. (2006). The future and the TALC. In R. W. Butler (Ed.), The tourism area life cycle vol. 1: Applications and modifications (pp. 281-290). Clevedon, UK: Channel View Publications.

Cohen, E. (1972). Towards a sociology of international tourism. Social Research, 39, 164-182.

Deery, M., Jago, L., \& Fredline, L. (2012). Rethinking social impacts of tourism research: A new research agenda. Tourism Management, 33, 64-73.

Doxey, G. V. (1975). A causation theory of visitor-resident irritants: Methodology and research inferences. In The Impact of Tourism, Sixth Annual Conference Proceedings (pp. 195-198). San Diego: Travel Research Association.

Gibson, P., \& Bentley, M. (2006). A study of impactsCruise tourism and the south-west of England. Journal of Travel and Tourism Marketing, 20(3/4), 63-77.

Haley, A. J., Snaith, T., \& Miller, G. (2005). The social impacts of tourism: A case study of Bath, UK. Annals of Tourism Research, 32(3), 647-668.

Hampton, J. (2013). Akaroa locals fed up with tourists. TV3 News Report. Retrieved July 31, 2014, from http:// www.3news.co.nz/Akaroa-locals-fed-up-with-tourists/ tabid/421/articleID/290530/Default.aspx

Harril, R. (2004). Residents' attitudes toward tourism development: A literature review with implications for tourism planning. Journal of Planning Literature, 18(3), 25-266.

Hritz, N., \& Cecil, A. (2008). Investigating the sustainability of cruise tourism: A case study of Key West. Journal of Sustainable Tourism, 16(2), 168-181.

Keller, C. P. (1987). Stage of peripheral tourism developmentCanada's Northwest Territories. Tourism Management, 8(1), 20-32.

Kim, K., Uysal, M., \& Sirgy, M. J. (2013). How does tourism in a community impact the quality of life of community residents? Tourism Management, 36, 527-540.
King, B., Pizam, A., \& Milman, A. (1993). Social impacts of tourism: host perceptions. Annals of Tourism Research, 20(4), 650-655.

Klein, R. (2002). Cruise ship blues: The underside of the cruise industry. Gabriola Island, Canada: New Society Publishers.

Lester, J., \& Weeden, C. (2004). Stakeholders, the natural environment and the future of Caribbean cruise tourism. International Journal of Tourism Research, 6, 39-50.

Pearce, P. L., Moscardo, G., \& Ross, G. F. (1996). Tourism community relationships. Oxford, UK: Pergamon.

Prideaux, B. (2000). The resort development spectrum-A new approach to modelling resort development. $\underline{\text { Tourism }}$ Management, 21(3), 225-240.

Radio New Zealand Newswire. (2013). Akaroa is bracing for a busy day as 4 cruise ships visit. Retrieved July 31, 2014, from http://www.knowledge-basket.co.nz/databases/ newztext/

Shone, M. C., Simmons, D. G., \& Fairweather, J. R. (2003). Evolving community response to tourism in Christchurch and Akaroa (Report Number 34). Canterbury, New Zealand: Tourism, Recreation Research and Education Centre (TRREC), Lincoln University.

Sleeman, R. (2008). Akaroa carrying capacity: Issues and options report. Prepared for Christchurch City Council.

Sleeman, R. (2009). Akaroa carrying capacity (Report Number 10). Canterbury, New Zealand: Centre for Land, Environment and People, Lincoln University.

Statistics New Zealand. (2014). 2013 Census QuickStats about a place: Akaroa. Retrieved June 21, 2014, from http://www.stats.govt.nz/Census/2013-census/profileand-summary-reports/quickstats-about-a-place

Stewart, E. J., Dawson, J., \& Draper, D. (2011). Cruise tourism and residents in Arctic Canada: Development of a resident attitude typology. Journal of Hospitality and Tourism Management, 18(1), 95-106.

Thompson, S. (2006). Akaroa summer traffic survey 2005/ 2006. Prepared for Opus Consulting, Banks Peninsula District Council.

Thompson, S. (2007). Akaroa summer traffic survey 2006/ 2007. Prepared for Asset and Network Planning Unit, Christchurch City Council.

Thompson, S. (2008). Akaroa summer traffic survey 2007/ 2008. Prepared for Asset and Network Planning Unit, Christchurch City Council.

Weaver, D. B. (2000). A broad context model of destination development scenarios. Tourism Management, 21(3), 217-224.

Weeden, C., Lester, J., \& Thyne, M. (2011). Cruise tourism: Emerging issues and implications for a maturing industry. Journal of Hospitality and Tourism Management, 18, 26-29.

Wilson, J., \& Shone, M. (2013). A survey of community attitudes to Akaroa hosting cruise ship arrivals. Report prepared by Lincoln University for Christchurch and Canterbury Tourism (CCT). Retrieved from http://hdl. handle.net/10182/5739 